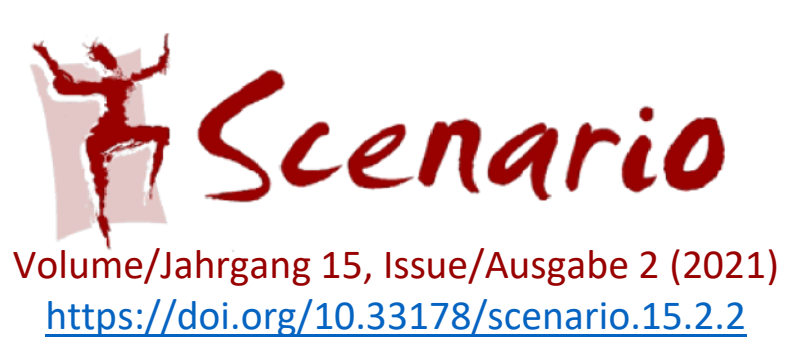

\title{
Performative education inside and outside the ethics of care
}

\author{
Three provocations
}

Anna Costantino

Inspired by the provocations raised in Cañas' RISE manifesto (2015), this essay argues that language learning, language teaching, and performative activities are caring acts. They are qualitative offerings that manifest themselves as embodied, relational, and artful events concerned with fostering fairer and caring societies. I refer to them as qualitative acts of care. The essay also voices concerns regarding the structural constraints faced by language educators and educational practitioner-researchers when they seek to enact language learning, arts practice, or practice-based research as caring and ethical work. Qualitative care is an ever-changing process that is often difficult to capture (both conceptually and experientially) in the flow of practice, which raises epistemological questions about the way qualitative care is measured and deemed to be self-sufficient and self-contained. Paradoxically, measurement and evaluation turn qualitative care into practices that are referred to here as quantitative acts of care. The essay does not provide readers with answers to the problems raised by Cañas (2015). Rather, from the reflexive standpoint of a language teacher and practitioner-researcher, it suggests the need to leverage the qualities of performative learning and teaching by making any work of care a continual endeavour.

\section{Introduction}

In this essay, I address the provocations raised by Cañas' RISE manifesto (2015), using them as prompts to voice concerns and raise open-ended questions regarding language and performative education as caring and ethical work. Here, Cañas' provocations are not stitched into a tight argumentative fabric; rather, they solicit reflections and three further provocations. They act as a counterpoint to discuss the constraints of my own practice as a language teacher and practitioner-researcher, using performative activities as explorative tools to investigate and understand the life of my classroom. Cañas' provocations also prod my argument. Learning and teaching, which includes performative activities, are caring acts. They are qualitative offerings that manifest themselves as embodied, relational, and artful events concerned with fostering fairer and caring societies. This is what is referred to here as qualitative care. This type of care is often difficult to capture both conceptually and experientially because, in the flow of practice, qualitative care is an ever-changing process. The nature of qualitative care, thus, raises epistemological questions about how this very 
process can be received within research processes and in practices. Indeed, qualitative care is in continual tension with forms of care that are allocated and measured and deemed by individuals and research to be self-sufficient and self-contained. This paradoxically turns qualitative care into practices that are referred to here as quantitative acts of care or, more provocatively, careless acts of care.

To picture how the RISE manifesto (2015) has resonated with my educational practice and prompted my reflections, I first frame the idea of care conceptually, arguing that it is an inherent quality of teaching and learning practices. I do so by drawing a parallel with and tapping into some of the issues addressed in Performing Care: New Perspectives on Socially Engaged Performance (Stuart Fisher \& Thompson, 2020), an edited collection discussing the relationship between care and socially engaged performance. The understanding of socially engaged arts practices as acts of care strongly resonates with my overall view of pedagogical activities and even more so with my take on performative activities applied to language pedagogy. This provides a blueprint to introduce my context of practice and discuss how I have experienced the dialectic of qualitative-quantitative care in my day-to-day practice while using classroom activities, such as performative activities, as exploratory tools in my classroom enquiries, against the backdrop of structural hindrances. Just as Cañas' provocations call for discussion of how this qualitative-quantitative tension affects performative learning and teaching, this essay delves into the epistemological constraints placed upon acts of qualitative care in contemporary modes of communicating knowledge and understanding. Its three provocations interrogate the ways in which datafication and pressurised academic work environments make enacting such acts of care a struggle. The essay's concluding reflections do not resolve the tension between qualitative and quantitative care, nor do they respond to the problems raised by Cañas (2015); however, they suggest a way to leverage the very qualities of performative learning and teaching by making any work of care a continual endeavour.

\section{Provocation \#1. (Performative) teaching and learning are acts of caring care}

In Performing Care (Stuart Fisher \& Thompson, 2020), the authors make several claims in relation to socially engaged arts practice, which can be used to map critical points to engage in a conversation with Cañas' provocations (2015). First, the essays in the collection touch upon the inherently caring nature of arts practice. Indeed, its case studies refer to a range of contexts, including care homes (Lloyd, 2020), youth theatres (Baker \& Inchley, 2020; Gallagher \& Turner-King, 2020), healthcare contexts (Houston, 2020; Jennings et al., 2020) and refugee centres (Parry-Davies, 2020). Moreover, as these contributions pinpoint what an 
ethic of care is, they identify some of the challenges of enacting care and bring to the fore the tension between qualitative and quantitative care.

Drawing critically upon some of the theorisations developed in the "ethics of care" scholarship (Held, 2006; Tronto, 1993), the volume's argument centres on the contention that performance and care are grounded upon an acknowledgement that humans are radically interconnected. As humans are intrinsically social and relational, they do not interact with each other unrelatedly; rather, they shape their identity dynamically by being situated within a web of relationships (Hamingston, 2020; Stuart Fisher, 2020; Stuart Fisher \& Thompson, 2020; Thompson, 2020). Care is, thus, a relationship that emerges contextually and calls for embodied vicinity, which means attending to the idiosyncratic richness of the ecologies cared for, what is specific about them and how one can meet the needs emerging within their inner interactions (Hamingston, 2020).

A caring practice is also "a holistic and integrated investment of thought, sensation and emotion" expressed through the body (Hamingston, 2020, p. 25). Care is imbued with a distinct aesthetic quality (Thompson, 2020). As Hamingston (2020) puts it:

\begin{abstract}
At the most experiential level, all care is received and delivered through the body. Our bodies are the epistemological and imaginative basis for care. We first grasp care through the senses in the satisfaction of needs. As we grow and develop to intellectualise care, the source of understanding remains the body. Many of our metaphors, including those for sympathetically appreciating others, are grounded in schemas of the body [...]. I understand the value of feeding, protecting, or comforting someone because I have been fed, protected, and comforted. I can conjecture about elaborate social systems that augment care, such as health care or welfare, but ultimately the success or failure of these imagined systems rests with the experience of individual bodies in relation with other bodies. Our bodies not only retain muscle memory, they provide originary metaphors for understanding experience including the experience of others. (p. 25)
\end{abstract}

Socially engaged performance also embodies the qualities of a caring relationship, as it is practical and made up of emotional acts concerned with how we engage with other people with affection, attentiveness, and responsiveness (Held, 2006; Noddings, 2013; Stuart Fisher \& Thompson, 2020). These practices also have a political and ethical scope. They entail values and understandings concerning how we should relate to one another in the world (Stuart Fisher, 2020).

However, there is often a gap between the ethical ideal and the systemic resources allocated to its pursuit and attainment. The socially engaged practices featured in Performing Care (Stuart Fisher \& Thompson, 2020) narrate sound experiences of quality care. They are 
centred on relationality, relatedness, and aesthetic embodiment, and enacted by performers and social actors together (e.g., young people, women, refugees, nurses, and social workers). The case studies also hint, however, that those performative practices face a major challenge in the current social and political climate. Resources are budgeted and sparsely allocated to those who have a deficit of care as well as to those who are in charge of providing it. As argued by Stuart Fisher (2020), caring practices driven by technocratic approaches revolve around quantifiable and deliverable outputs, which can be easily coopted by neoliberal agendas to feed ideas of self-sufficiency and individualism. Indeed, neoliberal narratives justify the nature of quantified (and limited) provisions through paradigms that promote the values of autonomy and self-realisation rather than interrelationality. Thus, while the reported experiences are (performative) acts involving relational and expressions of embodied care, they also have to contend with quantified and quantifying care systems (Stuart Fisher \& Thompson, 2020).

As Stuart Fisher (2020) suggests, arts practice is pivotal for building "more equitable, just, and caring societies" (p. 17), which entails embracing a notion of care as "an embodied, practised, and artful phenomena" (p. 3). However, in times when political and social action is dominated by an understanding of care as quantity - a commodity "distributed" and "measured" by a politics of austerity and cuts (Stuart Fisher, 2020, p. 17), the question remains as to how to address the barriers to care, which are practical and epistemological, but also structural. As hinted in the volume (Stuart Fisher \& Thompson, 2020), rebalancing the power relation between qualitative and quantitative care is perhaps the greatest challenge facing socially engaged performance.

Both the conceptualisations of arts practice as care and its critique of the notion of quantitative care featured in Performing Care (Stuart Fisher \& Thompson, 2020) not only reverberate with the RISE manifesto's (2015) provocations, but they also resonate with the struggles I have experienced as a language educator and practitioner-researcher while seeking to understand care and to embody it in my teaching practice. Just as the issues identified in the volume and the suggestions advanced are paralleled in my educational experience, so are the challenges of enacting a notion of care as "an embodied, practised, and artful phenomena" (Stuart Fisher, p. 3) amidst the constraints of technocratic learning environments.

Like the studies reported in Performing Care (2020), language classrooms face the challenges that arise when management is driven by an interest in cost-effectiveness. Examples of these managerial practices are reduced contact hours, often based on assumptions about the self-contained and undifferentiated capabilities of individual learners. In the classroom, this means that learning objectives are time-bound deliverables dictating the expectations 
about the effective and efficient performances of learners and teachers. This also means overshadowing the caring practices mentioned earlier as embodied vicinity to the diverse fabric of classroom life and its ecologies: it means losing sight of the complexity of learners' capabilities and dynamics in a classroom. Concerns with failing to acknowledge the lives and the depth of human experiences in socially engaged research have been captured in one of the RISE manifesto (2015) provocations:

\section{Do not reduce us to an issue}

We are whole humans with various experiences, knowledge and skills. We can speak on many things; do not reduce us to one narrative. (Cañas, 2015)

Working through the tension between "distributed" care (Stuart Fisher, 2020, p. 17) and care as an opening to the diverse life of a classroom and its interconnectedness is what has marked my pedagogical work while teaching Italian to undergraduate students in the UK. This dialectic has also positioned my work as a practitioner-researcher working with Exploratory Practice (EP), a form of practitioner-research established in language education (Allwright \& Hanks, 2009; Miller et al., 2021). Experiencing this tension and the tendency to be overwhelmed by distributed care was a significant understanding I gained when I first became involved in an EP enquiry, which was part of a participatory continuous professional development project aimed at gaining a better understanding of our classrooms to enhance the quality of our language provision (Slimani-Rolls \& Kiely, 2018).

Joining the project intrigued me as I thought it could help understand some of the recurrent issues experienced in my language classes. I hoped to gain an understanding collaboratively with my fellow colleagues and language students. At the core of an EP enquiry stands a puzzle, a why-question, which is raised and investigated by both educators and learners. Puzzling is solicited by aspects of the mutual learning practice that calls for clarification and understanding. Why-questions serve as prompts to investigate the shared learning in the classroom. In these explorations, the puzzle is then addressed by making use of classroom activities as investigative tools. These activities play a crucial role in our common journey of discovery and are utilised sustainably so that the process of understanding learning does not represent a burden for either educators and learners by calling for extra time and work outside the classroom. The understanding is that the explorative process is a learning experience in itself. My early enquiry was prompted by the need to understand why my students were not responding to my feedback and did not perform well in their final tests (Costantino, 2018). Significantly, the puzzle I first developed to interrogate my own work, as well as those that have followed, mostly revolved around teaching deficits: for instance, "Why is it so difficult to teach student $\mathrm{X}$ how to conjugate verbs?" Even more significantly, 
several of the participatory puzzles investigated by my students focused on a learning deficit associated with the struggle to meet those deliverables: "Why can't I pronounce correctly?" "Why can't I speak although I understand?" "Why can't I conjugate verbs when I speak?".

Indeed, a crucial aspect of the understanding I gained in my early enquiry was the extent to which routinised classroom activities - pressured by equally routinised managerial protocols - obscured the real language capabilities of my learners. I re-considered the provision of some of my classroom communicative activities such as guessing games and jigsaws, but also less communicative ones such as grammar and vocabulary worksheets, so that the overall aim of their implementation remained language learning itself. Questioning the use of those activities was not what was at stake, as they belong to a long-standing pedagogical tradition in language education, which, in its own right has proven successful. Rather, the process of learning was enhanced by the extra dimension of working around our mutual puzzle. The focus was shifted from an implementation based on warping these activities to meet the learning objectives of the day to one seeking to understand why the students were not performing well with vocabulary and grammar accuracy. For example, pair- and group-work activities were used to practise the speaking skills in the target language; however, they were also used to discuss their mutual puzzles and reflect on learning. Thus, I was able to gain unique insights into their abilities, aspirations, expectations and specific classroom dynamics that I had not always been able to perceive. This was made possible by using a language teacher's pedagogical toolkit creatively and experimentally. In doing so, I was able to see that the students were more linguistically proficient than I had assumed. I was, also, able to grasp the extent to which their abilities were impaired by the fast pace imposed upon them by the timing of their test delivery.

It is in this way that classroom pedagogical activities implemented as investigative tools can be framed as instances of care - understood as embodied vicinity, "affection", "attentiveness", "responsiveness" (Held, 2006; Noddings, 2013; Stuart Fisher \& Thompson, 2020) and attunement (Lutzker, 2014). They allow educational practitioners to attend to the classroom complexity, which is a continuous process. Indeed, the process of understanding requires coming to terms with the intricacy of emotional, cognitive and practical ecologies that constitute the dynamics of learning. This takes time and cannot be achieved in one go.

Similarly, subsequent EP enquires were solicited by questions and puzzles prompted by concern with meeting objectives and performance standards, which has further proven how strenuous solving the dialectics between qualitative and quantitative care is. The understanding I have gained thus far in my enquiries would not have emerged had I not questioned my own assumptions in connection with the uncaring linearity of the 
technocratic arrangements in educational settings (e.g., students go from A to B in a predetermined amount of time).

As I continued my pedagogical work, the understanding I gained helped me to appreciate the potential of an EP investigation to challenge the conventional use of pedagogic activities solely as a means to meet a set of deliverables. For me, this has meant that all classroom activities are potentially caring and can make a difference. Moreover, working towards understanding the life of the classroom and unravelling its diversity and idiosyncratic nature in contrast to institutional arrangements that have embraced the accreditation of capabilities can be framed as a desire to foster more equitable and caring educational practices.

Performative activities have increasingly been given a broader space in my pedagogical enquiries. Performative education has been embedded in my language teaching since I learnt to design and implement role-play, total physical response (TPR) and storytelling activities in my pre-service language education programme. I implemented performative activities to facilitate the reinforcement of structures and lexicon, the development of fluency, the exploration of cultural specificities and the fostering of creativity and imagination in my language classroom (Hillyard, 2016; Lutzker, 2013). In recent years, I have also adopted participative performative activities with my learners.

For example, following the brainstorming and writing of a puzzle in class, I have paired students with similar learning concerns. Then, I have asked them to imagine a learning scenario based on their puzzle and to enact it in front of their fellow students in the target language. The students in the audience had to react to it. The aim was for the performing students to present their puzzle better and for the students watching the performance to focus on how they could relate to it and expand their own. The implementation of these activities occurred with and without a script, to both practise and consolidate language, but also to understand my classroom. As mentioned earlier, I have used such activities as pedagogical tools, although not solely aimed at gaining linguistic proficiency, per se. I have used them as investigative tools to explore and understand together the complexity of our learning environment and enhance the quality of life of our classroom. However, the activities were not framed as research interventions to prove how efficient and effective they were for acquiring linguistic proficiency. When an enquiry was part of an educational initiative carried out with fellow colleagues, I planned their implementation. However, I have also used materials and activities impromptu in response to critical instances emerging from the flow of classroom activities, such as when noticing that students were particularly involved in a previously planned activity and the activity could be further developed. 
Performative activities offer greater scope to de-routinise pedagogic tools. As classroom activities, they potentially involve the attributes of quality care noted earlier based on how they are approached. However, their scope rests in their embodied aesthetic attributes, which bring together "thought, sensation, and emotion" (Hamingston, 2020, p. 25) through the body. These qualities facilitate an understanding of learning - often serendipitously. They have the potential to make and remake meaning(s), casting students into what Engeström (2016) calls learning "what is not yet there."

For instance, while working around and through a puzzle, I make a pedagogical and conventional use of video-clips to practise vocabulary and elicit descriptive narratives. Whether they are short films or songs, these types of materials feature rounded narratives of conflicts about which students are invited to provide answers halfway through, either argumentatively or by entering a character, as in Forum Theatre (Boal, 2000). Through the character they impersonate, students are encouraged to relate the collective resolution of a conflict or downfall to their personal learning story. Therefore, this type of activity allows me to explore students' attitudes towards learning and the way they learn, while simultaneously investigating my own puzzle. It, also, allows them to discover what type of learner they are while exploring their own puzzles. A character game allows learners to live through what I referred to earlier as "relatedness" - people being bound to care for each other both synchronically and diachronically. The classroom space can be viewed as linking: (a) the cognitive, emotional, and practical self, situated in the here-and-now; (b) the past self through memories and recollections; and (c) the future self through desire and aspirations. By exploring their current learning, students can gain an awareness of how their identities are being shaped through learning and relate to their past experiences and previous knowledge.

Performative activities offer learners opportunities to catch glimpses of and become attuned to fundamental human and social entanglement. In an equally shared space, these activities connect life inside and outside the classroom (Bateson, 1973; Engeström, 2016). This unveils the multi-layered dimensions that inhabit a language classroom ecology (Kramsch, 2002; Larsen-Freeman, 2012), bringing to the surface learning as a qualitative process. Enabling a shared learning experience helps students to blur the initial sense of deficit, which tends to emerge when a puzzle is first framed, to become aware of their capabilities and, thus, build a sense of self-efficacy.

To a practitioner-researcher, working with traditional classroom activities as explorative tools means that the boundaries between work for pedagogical development (Norton, 2019) and classroom research overlap. In other words, engaging with materials development and carrying out research are part of the same endeavour: enhancing the learning occurring in 
class, which adds an extra layer of complexity. As the boundaries of the two remits fade, seeking to contain the understandings gained in a pedagogical enquiry into a pedagogical procedure, creating a set of classroom activities or even findings is a challenge in itself. As a practitioner-researcher does not stand as a detached observer in the classroom, but participates in its activities, insights are gained on the spur of the moment. At times, I enter them in a diary, when they appear significant. At times, those insights remain hazy, while at other times, they spring retrospectively from pictures I take of learners' work. Some have materialised into a set of understandings, when I saw they substantiated a theme that could be disseminated. However, those understandings have always been superseded by a new set of understandings gained from the next puzzle, without invalidating the previous ones.

In current educational arrangements, it is pivotal to make learning outcomes, research findings and evidence of impact visible, as I illustrate later, which makes the dialectic qualitative-quantitative care even more burdensome. For an EP practitioner-researcher, in many ways, the dissemination of understandings derived from an enquiry is crucial. Dissemination allows scholars to gain institutional support, capture practical nuances that would otherwise be lost in repetitive classroom routines and, importantly, engage in discussion with their communities of practice. The latter provides critical validation of the understandings that emerge from enquiries, which are often conducted in the unseen confines of a classroom.

Therefore, having to make visible the process of an enquiry, and the resulting understandings for dissemination, raises the question: How much visibility can the dynamic of learning and understanding afford before it loses the unique and ephemeral quality of an ever-changing continuum of lived experience? This question touches upon another critical point: Making the understandings of a practitioner enquiry visible entails transforming understandings into data. Data, as an index of visibility, raise two more interconnected questions: To what extent can data remain faithful to the richness of the learning experiences it represents? To what extent can an educational practitioner represent something that cannot easily be datafied?

These questions take the tension between qualitative-quantitative care to the next level of analysis because they concern the modes in which understandings, findings, and experiences are communicated to the external world. For educational practitioners, modes of communication and quantification often make caring work a struggle. Measurable deliverables - whether they are learning objectives, understandings, or findings - contribute to the reproduction, dissemination, and generation of information to satisfy the demands of the knowledge economy (Lupton et al., 2018). Current conditions are such that teaching, and scholarship conducted on a micro level are "an engine to power economic demands for 
growth" (Lupton et al., 2018, p. 3). For deliverables to have an impact on national growth and innovation, they must enjoy global visibility. Therefore, they must be presented in a format that is accessible to a wide audience. The problem, however, is not about communicating understandings or findings to a broader audience; rather, it is the privileging of quantity over quality which leaves little room for embodied, sensuous pedagogical practices and research, such as those illustrated earlier. For academics, this very often translates to experiencing their own caring acts of care as a "labour of care" (Gill, 2016), which is undervalued and unseen within the constraints of a quantified academe operating within a neoliberal environment. These arrangements call for considering another provocation by Cañas (2015), which seems to remind researchers of the importance of defining their own positionality:

\author{
Realise your own privilege \\ What biases and intentions, even if you consider these good intentions, do \\ you carry with you? What social positionality (and power) do you bring to \\ the space? Know how much space you take up. Know when to step back.
}

While Cañas (2015) rightly points to the need to understand positionality, to a practitionerresearcher the problem remains as to whether and how those arrangements can be evaded in a quantified, data-driven environment.

\title{
3 Provocation \#2. Interrogating data infrastructures
}

Digital data and data infrastructures can provide imagery but also a fruitful critical lens to consider how data are communicated, their ability to represent lived experiences, and the extent to which researchers can capture the richness of lived experiences in the form of data. Academia has been at the forefront of the digital turn. It embraced the technological developments that began with the advent of the personal computer in the mid-1980s and the internet in the 1990s (Lupton et al., 2018). Those developments, which were systematically embedded in academic practices from the outset, have affected what teaching and scholarship entail (Lupton et al., 2018). Over the last three decades, the digitalisation of academic work has increased opportunities for universities to have more distributed forms of communication between peer academics and students. Digitalisation has also become integral to how the knowledge economy works. It has affected the modalities of work for educators and researchers, as well as how they perceive their work and themselves as academic professionals.

At the same time, academia has become an integral part of a globalised marketplace. Information, teaching, and scholarship are viewed as profitable commodities. Academic 
work unfolds in fast-changing and competing environments that are increasingly governed by an audit culture (Denzin, 2013), in which metrics are dictated by policies of economic accountability, efficiency, and effectiveness (Gourlay \& Stevenson, 2017; Gray \& Block, 2012; Lupton et al., 2018; Norton, 2019; Slaughter \& Rhoades, 2004). Under pressure to compete in national and global league tables while complying with quality assurance practices, accountability policies, and comparative performance benchmarking, academics must demonstrate excellence in teaching (Mockler \& Groundwater-Smith, 2017; Mockler, 2015; Norton, 2019; Stevenson et al., 2017; Thompson \& Cook, 2017) as well as in research (Burrows, 2012; Denzin, 2013; Jarke \& Breiter, 2019; Lupton et al., 2018; Piattoeva \& Saari, 2020). To achieve this, individual and institutional performance are monitored across the board through data from activities such as "publication counts, rankings, impact indices, collection of student feedback, and many others" (Piattoeva \& Saari, 2020, p. 2; see also Burrows, 2012; Piattoeva \& Boden 2020).

As infrastructures determine ways of behaving when teaching and conducting research, by tracking the impact of these activities, data become performative. This means that metrics and performance analytics become a way of being, feeling, and existing. Metrics enact logistics of investment or entrepreneurialism of the self (Thompson \& Cook, 2017), which not only abstracts the sensuous embodiment of practice, but also becomes the measure of an individual's self-worth (Foucault, 2008). An example of this can be seen in the realisation, noted earlier, that both we (the language teachers) and our students tend to frame our puzzlement as a deficit against benchmarks that we always fail to meet.

As the modes of "dataveillance" (van Dijck, 2014) become internalised and engineered to enable fast production, they also become introjected. As soon as data are collected to satisfy research questions and purposes, one's fieldwork is complete. The imperative is to move on to the next new thing. New findings and outcomes must be yielded - and fast! This is particularly true in countries like Australia (Lupton et al., 2018) and the UK (Gourlay \& Stevenson, 2017), which is the context of my academic practice. It is in such instances that the tension between qualitative and quantitative care can be recast as one between caring and uncaring acts of care.

Such arrangements very often concern academic work, which must demonstrate social and community impact, as research projects are made accountable for this broad societal task. The funded projects featured in Performing Care (2020) are examples of the societal tasks that governmental agencies expect from socially engaged arts practices. For example, the verbatim theatre methodologies discussed by Inchley and Baker (2020) offer young people in state care opportunities for self-narration, which allows them to disrupt bureaucratic narratives that make them feel objectified. Another example is Clean Break Theatre 
(McAvinchey, 2020), an organisation that provides care to women experiencing the criminal justice system, which helps them unmask the oppressions that define their lives. While community research projects are expected to be caring and impactful, they are also bound by and limited to the financial resources available and the timing of pre-determined deliverables. Thus, projects define the nature, distribution, and end of care as well as assumptions about the right amount of care required to meet the project's objectives (Stuart Fisher, 2020). Support care is provided through modalities that can be foreseen, generalised, and encompassed by a time-bound project. This type of provision rests upon the assumption that an individual can reach a full and final state of fulfilment. Once care has been provided according to the initial parameters, the project comes to an end.

As Cañas (2015) points out:

\begin{abstract}
Participation is not always progressive or empowering
Your project may have elements of participation but know how this can just as easily be limiting, tokenistic, and condescending? Your demands on our community sharing our stories may be just as easily disempowering. What frameworks have you already imposed on participation?? What power dynamics are you reinforcing with such a framework? What relationships are you creating (e.g., informant vs. expert, enunciated vs. enunciator)?
\end{abstract}

As Mejias and Couldry (2019) have argued, datafication is "the wider transformation of human life so that its elements can be a continual source of data" (p. 2). Datafication unfolds processes of quantification that generate different kinds of value from the original data. To put it in van Dijck's (2014) words, datafication is a form of "life mining", because datafication processes ultimately extract knowledge and information from human and social life (Couldry, 2020; Couldry \& Mejias, 2019; Mejias \& Couldry, 2019). The process of quantification of life implies abstraction, which transforms the "flow of social life and social meaning into streams of numbers that can be counted" (Mejias \& Couldry, 2019, p. 3).

Because quantification requires mechanisms of data collection, processing, and storage, the production of value and data management occurs through the infrastructures created to contain and manage data. The process of generating value out of data is accompanied by "monetisation, but also means of state control, cultural production, [and] civic empowerment" (Mejias \& Couldry, 2019, p. 4). As van Dijck (2014) has argued, datafication as "life mining" constitutes a new scientific paradigm for understanding sociality and social behaviour. This paradigm is pursued by "entrepreneurs, academics, and state agencies" and relies on the positivistic re-proposition of "a belief in the objectivity of quantification and in the potential of tracking all kinds of human behavior and sociality" (van Dijck, 2014, p. 201). 
Once again, this strongly resonates with the concerns expressed in Performing Care (2020) and my own concerns about educational practice.

A research project, as a main data infrastructure, is also imbricated with other infrastructures, such as: (a) the programme rendering raw data into meta-data; (b) the media platforms involved in the dissemination of the initial and final project; (c) the institutional infrastructures that support the project; and, ultimately, (d) those infrastructures within which the institutional infrastructures themselves sit as recipients of public funds, such as the research bodies that invest in the project completion or evaluate its outcomes. One important infrastructure is the ethical approval system, which collates and stores data to ensure that the research project provides voluntary informed consent, privacy, and confidentiality, with the aim of protecting humans from harm (Norton, 2019). Once data concerning the research project satisfy ethical requirements, the project is completed, at least from the viewpoint of the ethics system. However, the question is how safe a research environment is after a participant signs the consent form? Or, as Cañas (2015) puts it:

\section{It is not a safe-space just because you say it is}

This requires long term grass-roots work, solidarity, and commitment.

Data infrastructures are integral to contemporary social systems. The drive to accumulate data transforms not only how work is done but how individuals see themselves and their work. Data may be inescapable, but it is nonetheless essential to question how data practices function and their impact on individuals. Data as the systematic collection of pieces of information are important to academic interpretative work, as well as to work beyond academia. Viewing data as raw material for generating knowledge from a specific context under investigation is not the issue at stake here.

There are downsides to the creation and handling of data. As illustrated earlier, caring acts of care are difficult to convert into data when the investigative medium is reflexivity, because of the ever-changing nature of classroom occurrences. Check-box processes, such as those for verifying consent and safety, may ignore or miss important modulations in participation, perception, and lived experience. In addition, the perpetual drive for the next process or new thing may neglect important lessons and gains derived from maintaining focus on a particular project or a classroom dynamic.

Contemporary explorations of datafication and "dataism" (van Dijck's, 2014) shed further light on the ways an ethics of care is hindered in current academic environments. According to Kitchin (2014), data are "the raw material produced by abstracting the world into 
categories, measures, and other representational forms - numbers, characters, symbols, images, sounds, electromagnetic waves, bits - that constitute the building blocks from which information and knowledge are created" (p. 1). As Mejias and Couldry (2019) point out, "any thing or process (from a sun or rain pattern, to a beating heart, to a lesson delivered in a class) can be made into data" (p. 2), which is not a novel phenomenon. Moreover, many benefit from data, not only corporations and states, but also civil society organisations and communities (Mejias \& Couldry, 2019).

From the perspective of educational research and practices, dataism can be streamlined into three major processes: (a) human and non-human life is viewed as a mine of extractable resources; (b) once extracted, life (as a bundle of resources) is datafied according to the value attributed to it by those who claim ownership of the datafied resources - normally the actors who initiated the process of datafication; and (c) datafied life gains a life of its own, independent from the original source. The process of abstraction from actual lived experience to data independent of lived reality relates to the ways in which care is understood and distributed in educational settings. The question that needs to be interrogated is to what extent datafication processes hinder the enacting of care that is embodied, relational, practised, continuous, artful, creative, and innovative.

Cañas (2015) seems to have provocatively framed this concern as a call for reflexivity:

\section{Critically interrogate your intention}

Our struggle is not an opportunity, or our bodies a currency, by which to build your career. Rather than merely focusing on the other (Where do I find refugees?.. etc) Subject your own intention to critical, reflexive analysis. What is your motivation to work with this particular subject matter? Why at this particular time?

If reflexivity qualifies as a suitable framework for the ethical enquiring of embodied and creative practices, the question is how to enact reflexivity.

\section{Provocation \#3: Research, teaching, and learning can be care-ful}

According to Law and Lin (2020), good research is "care-ful" research that involves concerns, research questions, and sensibilities. Sensibilities include an "openness to material heterogeneities, webby relations, non-coherence, otherness, and normativities and politics" (p. 1). They also imply insensibilities and invisibility. What is made visible is simultaneously and inextricably linked to what is made invisible. As research methodologies "enact particular realities," they also "choke off others" (Law, 2021, p. 1). 
In my work, the flow of lived and entangled experiences forms a link between the understanding gained at the time of the activity and what was recorded or preserved as data. As mentioned earlier, as soon as I move on to another puzzle or a new pedagogic activity, my previously gained understandings are already part of an ever-changing pool of unique living events. Placing an emphasis on the unending flow of enquiry allows embodied experiences to re-emerge, remake, and nourish new meaning. Tracing the lived agency of the participants involved in a research project or classroom enquiry helps keep alive the connection between unique living events and their communication through remediated forms. Learning experiences in general, and performative experiences in particular, are unique living events that involve the embodied vicinity of participant learners. It is essential to recognise the difference between the performative moment and how it is represented through datafication. Truthful performative research and learning should be always attuned to lived experience and the flow of life. However, the abstraction inherent in datafication makes it difficult to remain faithful to the heterogeneity and messiness of lived experiences. One of Cañas' (2015) provocations touches upon this very problem:

\section{Presentation vs representation}

\section{Know the difference!}

Mindful enquiry as "care-ful research" (Law, 2021; Law \& Lin, 2020) recognises that "knowledge and artefacts are shaped by and in turn shape the social within down-to-earth and somewhat unruly practices" (Law \& Lin, 2020, p. 1). Practitioners engaged in pedagogical practices can benefit from the approach, which recognises the heterogenous nature of researchers' tools, the power relationships within which scientists operate, and the pretence of scientific neutrality. Indeed, the research apparatus involves

[e]mbodied skills, educated forms of perception, instruments for sensing, techniques for turning observations into numbers, protocols for coding up, combining and moving findings from one location to others, plus conventions about appropriate literary forms. All of these are embedded in equally necessary social and institutional arrangements, assumptions about authority, and power. (Law, 2021, p. 1)

Similar insights are captured in Cañas' manifesto (2015):

\section{Art is not neutral}

Our community has been politicised and any art work done with/by us is inherently political. If you wish to build with our community know that your artistic practice cannot be neutral. 
Some of the features of care-ful research relate well to my take on classroom enquiry and performative teaching. Engaging with "embodied, practised, and artful" arts practice (Stuart Fisher, 2020) is also about a number of concepts mentioned by Law (2021): "cultivating a vivid awareness of tensions, multiplicities, and difference"; "holding things together"; being "iterative"; being "modest"; being "sensitive to changing exigencies, concerns, tensions, and forms of othering"; being "slow"; and being "uncomfortable" (p. 4). Similarly, Mortari (2018) proposes that when the object of an enquiry is lived experience, embracing "the principle of delicacy becomes an unavoidable ethical move" (p. 12). This counteracts a positivistic approach, which deploys "a framework of preconceived formulae" and enacts "a logic of power over things" (p. 6). The features Mortari (2008) indicates echo those of Law (2021). Mortari's (2008) "ethic of delicacy" is about:

- berry-picking vs hunting

- cultivating a receptive disposition

- learning to think poetically

- moving with slow gestures

- observing patiently.

To a practitioner-researcher, exercising reflexivity might be one way of enacting care-ful research and, thus, dealing with the challenges involved in understanding the complexity of practices in a non-predatory manner. To language teachers, exploring their practice through their artistry is another way of facing the constraints deriving from academic work environments. However, such an endeavour should be an intentional stance from the outset. It cannot fully resolve the tension between qualitative and quantitative care, but it can stress the need to make the work of care a continual enterprise.

\section{Bibliography}

Allwright, D., \& Hanks, J. (2009). The developing language learner: An introduction to Exploratory Practice. Palgrave Macmillan. https://doi.org/10.1057/9780230233690

Baker, S., \& Inchley, M. (2020). Verbatim practice as research with care-experienced young people: An 'aesthetics of care' through aural attention. In A. Stuart Fisher \& J. Thompson (Eds.), Performing care: New perspectives on socially engaged performance (pp. 171-186). Manchester University Press. https://doi.org/10.7765/9781526146816.00021

Bateson, G. (1973). Steps to an ecology of mind. University of Chicago Press.

Boal, A. (2000). Theatre of the oppressed. (A. Charles, M. Leal McBride, \& E. Fryer, Trans.) London: Pluto Press. (Original work published 1979). 
Burrows, R. 2012. Living with the H-Index?: Metric assemblages in the contemporary academy. The Sociological Review 60(2), 355-372. https://doi.org/10.1111/j.1467-954X.2012.02077.x

Cañas, T. (2015). 10 things you need to consider if you are an artist - not of the refugee and asylum seeker community - looking to work with our community. RISE: Refugees, Survivors and ExDetainees. https://www.riserefugee.org/10-things-you-need-to-consider-if-you-are-an-artist-notof-the-refugee-and-asylum-seeker-community-looking-to-work-with-our-community/

Costantino, A. (2018). A written feedback puzzle: Understanding 'local' pedagogy. In A. Slimani-Rolls \& R. Kiely (Eds.), Exploratory practice for continuing professional development: An innovative approach for language teachers (pp. 119-133). Palgrave Macmillan. https://doi.org/10.1007/9783-319-69763-5 7

Couldry, N. (2020). Recovering critique in an age of datafication. New Media \& Society, 22(7), 11351151. https://doi.org/10.1177/1461444820912536

Couldry, N., \& Mejias, U. A. (2019). The costs of connection: How data is colonizing human life and appropriating it for capitalism. Stanford University Press. https://doi.org/10.1515/9781503609754

Denzin, N. K. (2013). The Death of Data? Cultural Studies $\leftrightarrow$ Critical Methodologies, 13(4), 353-356. https://doi.org/10.1177/1532708613487882

Engeström, Y. (2016). Studies in expansive learning: Learning what is not yet there. Cambridge University Press. https://doi.org/10.1017/CBO9781316225363

Foucault, M. (2008). The birth of biopolitics: Lectures at the Collège de France, 1978-1979 (G. Burchell, Trans.). Palgrave Macmillan. (Original work published 1978-1979)

Gallagher, K., \& Turner-King, R. (2020). Performing a museum of living memories: Beholding young people's experiences and expressions of care through oral history performance. In A. Stuart Fisher, \& J. Thompson (Eds.), Performing care: New perspectives on socially engaged performance (pp. 139-155). Manchester University Press. https://doi.org/10.7765/9781526146816.00018

Gill, R. (2016). Breaking the silence: The hidden injuries of neo-liberal academia. Feministische Studien, 34(1), 39-55. https://doi.org/10.1515/fs-2016-0105

Gourlay, L., \& Stevenson, J. (2017). Teaching excellence in higher education: Critical perspectives. Teaching in Higher Education, 22(4), 391-395. https://doi.org/10.1080/13562517.2017.1304632

Gray, J., \& Block, D. (2012). The marketisation of language teacher education and neoliberalism: Characteristics, consequences and future prospects. In D. Block, J. Gray, \& M. Holborow (Eds.), Neoliberalism and applied linguistics (pp. 119-148). Routledge. https://doi.org/10.4324/9780203128121-10

Hamingston, M. (2020). Care ethics and improvisation: Can performance care? In A. Stuart Fisher, \& J. Thompson (Eds.), Performing care: New perspectives on socially engaged performance (pp. 2135). Manchester University Press.

Held, V. (2006). The ethics of care: Personal, political, and global. Oxford University Press. 
Costantino: Performative education inside and outside the ethics of care

Hillyard, S. (2016). English Through Drama: Creative Activities for Inclusive ELT Classes. Helbling Languages.

Houston, S. (2020). Caring beyond illness: An examination of Godder's socially engaged art and participatory dance for Parkinson's work. In A. Stuart Fisher, \& J. Thompson (Eds.), Performing care: New perspectives on socially engaged performance (pp. 69-84). Manchester University Press.

Jarke, J., \& Breiter, A. (2019). The datafication of education. Learning, Media and Technology, 44(1), 1-6. https://doi.org/10.1080/17439884.2019.1573833

Jennings, M., Deeny, P., \& Tizzard-Kleister, K. (2020). Acts of care: Applied drama, 'sympathetic presence' and person-centred nursing. In A. Stuart Fisher \& J. Thompson (Eds.), Performing care: New perspectives on socially engaged performance (pp. 187-203). Manchester University Press.

Kitchin, R. (2014). The data revolution: Big data, open data, data infrastructures and their consequences. Sage. https://doi.org/10.4135/9781473909472

Kramsch, C. (Ed.). (2002). Language acquisition and language socialization: Ecological perspectives. Continuum.

Larsen-Freeman, D. (2012). Complex, dynamic systems: A new transdisciplinary theme for applied linguistics? Language Teaching, 45(2), 202-214. https://doi.org/10.1017/\$0261444811000061

Law, J. (2021). From After Method to care-ful research. Heterogeneities. http://www.heterogeneities.net/publications/Law2021FromAfterMethodToCare-fulResearch.pdf

Law, J., \& Lin, W. Y. (2020). Care-ful research: Sensibilities from STS. Heterogeneities. http://ww.heterogeneities.net/publications/LawLin2020CarefulResearchSensibilitiesFromSTS.pdf

Lloyd, J. (2020). Taking care of the laundry in care homes. In A. Stuart Fisher \& J. Thompson (Eds.), Performing care: New perspectives on socially engaged performance (pp. 204-214). Manchester University Press. https://doi.org/10.7765/9781526146816.00023

Lupton, D., Mewburn, I., \& Thomson P. (2018). The digital academic: Identities, contexts and politics. In D. Lupton, I. Mewburn, \& P. Thomson (Eds.), The digital academic: Critical perspectives on digital technologies in higher education (pp. 1-19). Routledge.

Lutzker, P. (2013). Beyond semantics: Moving language in foreign language learning. In B. Tomlinson (Ed.). Applied Linguistics and Materials Development (pp. 31-42). Bloomsbury.

Lutzker, P. (2014), Attunement and Teaching, Rose, Research on Steiner Education, 5(Special issue), 65-72.

McAvinchey, C. (2020). Clean Break: A practical politics of care. In A. Stuart Fisher \& J. Thompson (Eds.), Performing care: New perspectives on socially engaged performance (pp. 123-138). Manchester University Press. https://doi.org/10.7765/9781526146816.00017

Mejias, U. A., \& Couldry, N. (2019). Datafication. Internet Policy Review, 8(4). https://doi.org/10.14763/2019.4.1428 
Miller, I. K., Cunha, M. I. A., \& Allwright, D. (2021). Teachers as practitioners of learning: the lens of exploratory practice. Educational Action Research, 29(3), 447-461. https://doi.org/10.1080/09650792.2020.1842780

Mockler, N. (2015). From surveillance to formation?: A generative approach to teacher "performance and development" in Australian schools. Australian Journal of Teacher Education, 40(9), 117-131. https://doi.org/10.14221/ajte.2015v40n9.7

Mockler, N., \& Groundwater-Smith, S. (2017). Teacher research: A knowledge-producing profession? In P. Grootenboer, C. Edwards-Groves, \& S. Choy (Eds.), Practice theory perspectives on pedagogy and education: Praxis, diversity and contestation (pp. 215-230). Springer. https://doi.org/10.1007/978-981-10-3130-4 11

Mortari, L. (2008). The ethic of delicacy in phenomenological research. International Journal of Qualitative Studies on Health and Well-being, 3(1), 3-17. https://doi.org/10.1080/17482620701747392

Noddings, N. (2013). Caring: A relational approach to ethics and moral education (2nd ed.). University of California Press. https://doi.org/10.1525/9780520957343 (Original work published 1984)

Norton, L. (2019). Action research in learning and teaching: A practical guide to conducting pedagogical research in universities (2nd ed.). Routledge. https://doi.org/10.4324/9781315147581

Parry-Davies, E. (2020). 'Still Lives': Syrian displacement and care in contemporary Beirut. In A. Stuart Fisher \& J. Thompson (Eds.), Performing care: New perspectives on socially engaged performance (pp. 156-168). Manchester University Press. https://doi.org/10.7765/9781526146816.00019

Piattoeva, N., \& Boden, R. (2020). Escaping numbers?: The ambiguities of the governance of education through data. International Studies in Sociology of Education, 29(1-2), 1-18. https://doi.org/10.1080/09620214.2020.1725590

Piattoeva, N., \& Saari, A. (2020). Rubbing against data infrastructure(s): Methodological explorations on working with(in) the impossibility of exteriority. Journal of Education Policy, 1-21. https://doi.org/10.1080/02680939.2020.1753814

Slaughter, S., \& Rhoades, G. (2004). Academic capitalism and the new economy: Markets, state and higher education. Johns Hopkins University Press.

Slimani-Rolls, A., \& Kiely, R. (2018). Exploratory practice in language education: How teachers teach and learn. In A. Slimani-Rolls \& R. Kiely (Eds.), Exploratory practice for continuing professional development (pp. 5-27). Palgrave Macmillan.

Stevenson, J., Whelan, P., \& Burke, P. J. (2017). 'Teaching excellence' in the context of frailty. In Pedagogic frailty and resilience in the university (pp. 63-77). Brill Sense.

Stuart Fisher, A. (2020). Introduction: Caring performance, performing care. In A. Stuart Fisher \& J. Thompson (Eds.), Performing care: New perspectives on socially engaged performance (pp. 1-17). Manchester University Press. 
Costantino: Performative education inside and outside the ethics of care

Stuart Fisher, A., \& Thompson, J. (Eds.) (2020). Performing care: New perspectives on socially engaged performance. Manchester University Press.

Thompson, G., \& Cook, I. (2017). The logic of data-sense: Thinking through learning personalisation. Discourse: Studies in the Cultural Politics of Education, 38(5), 740-754. https://doi.org/10.1080/01596306.2016.1148833

Thompson, J. (2020). Performing the 'aesthetics of care'. In A. Stuart Fisher \& J. Thompson (Eds.), Performing care: New perspectives on socially engaged performance (pp. 214-229). Manchester University Press. https://doi.org/10.7765/9781526146816.00024

Tronto, J. (1993). Moral boundaries: A political argument for an ethic of care. Routledge.

van Dijck, J. (2014). Datafication, dataism and dataveillance: Big Data between scientific paradigm and ideology. Surveillance \& Society, 12(2), 197-208. 